\title{
CODE MIXING AS LANGUAGE STYLE IN COMMUNICATION THROUGH SOCIAL MEDIA TWITTER
}

\author{
Putu Ega Meliani ${ }^{1}$, Ni Made Ratminingsih ${ }^{2}$, Gede Mahendrayana ${ }^{3}$ \\ 1,2,3) English Language Education, Ganesha University of Education \\ putuegameliani06@undiksha.ac.id ${ }^{1}$
}

\begin{abstract}
This paper aims to recognize the types of code-mixing and factors influencing code-mixing by Twitter users. This study uses a descriptive qualitative research design. The subject of this study is Twitter users who post tweets that contained code-mixing. The researcher uses documentation and interview as data collection methods. The data for identifying the types of code-mixing were collected by documenting the tweets posted previously by Twitter users on the Twitter platform. The interview guide was used to ask questions to respondents about the factors influencing the use of code-mixing in communication as language style. The data were analyzed through three stages: data reduction, data display, and conclusion: verifying. The data collected from documentation and interview showed that insertion code-mixing became the dominant type used among Twitter users. It is influenced by several factors from within of language speaker and external factors.
\end{abstract}

Keywords: Code-mixing, tweets, Twitter user

\section{Introduction}

Language is one of the important elements of communication in society. Silaban \& Marpaung (2020) define communication as a process of sharing information through oral and written communication. People need tools for transferring and receiving information from others. Therefore, language becomes a tool of communication to express thoughts, ideas, and wishes (Pratama \& Hastuti, 2020). Languages and humans are related to each other (Safitri et al., 2017). It cannot be used without humans, and they cannot communicate without that language. The language used in everyday life can describe a personality in conveying ideas or feelings (Syafaat \& Setiawan, 2019). However, the development of various cultures that spread widely in society slowly affects the language style used by speakers in communication. The language variations are increasingly diverse from different regions with respective characteristics. The existence of foreign culture and the development of linguistic globalization affect how the speakers communicate using the language with various language styles.

The emergence of influences from foreign cultures makes Indonesian people begin to adapt and learn about foreign languages, like English language. It is increasingly being studied by the language speaker since the rapid influence of globalization (Kurniawan, 2016). Language variation begins to develop rapidly since cultural and linguistic globalization plays an important role and affects communication style. It allows the languages to grow in certain places and influence the other languages, such as the English language in Indonesia. It affects the national language and regional languages among Indonesian people. It results in a decrease quality of language originality when two different languages are mixed. The language variety allows people to 
speak in more than one language between the national language, regional language, and foreign language. It is better known bilingualism and multilingualism. Nuraeni et al. (2018) explain bilingual means person who can communicate more than one language and develop other language skills as a second or foreign language. It is a phenomenon of sociolinguistic studies in society (Safitri et al., 2017).

Bilingual can affect how the speakers of language follow the rules of language (grammar) and adjusted to the language styles in communication. It also can affect the process of regulating language variations for communication, one of which is code-mixing. Syafaat \& Setiawan (2019) explain that various language styles that develop in society have further widened the opportunities for the code-mixing phenomenon to occur in social communication. Moreover, language speaker frequently use code-mixing in informal communication rather than formal context. The informal context does not prioritize the grammar rules used and focuses on conveying the information. It allows code-mixing to occur during communication among language speakers. Language speakers use code-mixing by mixing two different languages without changing the topic being discussed. It is identified as the use of two languages interchangeably.

The main language used is the matrix language (the first language or language that is frequently used in daily speech), and another language plays as the embedded language in the sentence (Leung \& Chan, 2016). The code of embedded language used in code-mixing is commonly a word, phrase, and clause
(Nuraeni et al., 2018). It is transferred and adopted from another language, such as a foreign language. Siddiq et al. (2020) states codes mixing in communication are not simply combining codes from different languages but require more knowledge and understanding of both languages and the cross-cultural norms of these languages used. Safitri et al. (2017) emphasizes that code-mixing uses code from a language inserted in a sentence or clause in oral or written communication. Code refers to letters, words, or symbols that can replace the meaning of words in a particular language (Sutrisno \& Ariesta, 2019). The choice of code depends on social factors such as accent, social class and adjusted to several communication styles, such as casual or intimate style, respectful style, or polite style of communication (Kurniawan, 2016).

Code-mixing frequently arises among social media users in the written and oral communication in informal context. Social media and language are closely related (Syafaat \& Setiawan, 2019). Social media becomes a forum that gathers people in online activities to communicate, interact, and allows people to search or share information with others (Sutrisno \& Ariesta, 2019). There are various social media platforms globally, and Twitter becomes one of the 21 most popular social media platforms in 2021 (https://finance.yahoo.com, accessed on May 22nd, 2021). Twitter has a feature to post short messages, better known as "tweets" (Samhan, 2017). The tweets posted by Twitter users previously can be seen by the public and directed to certain people who have an account. Syafaat \& Setiawan (2019) explain that Twitter users are given the freedom to write anything as 
long as they follow the Twitter platform rules.

Twitter is one of the well-known applications widely used by various groups, such as teenagers, influencers, artists, public figures, and others, to share thoughts or information in the form of text. Syafaat \& Setiawan (2019) also states that bilingual people who are Twitter users often mix bilingual vocabulary in a post/tweet. Therefore, Twitter becomes the focus of social media platforms in this paper. Analyzing code-mixing in Twitter posts among Twitter users is essential to know the influence of language ability in language style for written communication through social media, especially Twitter. The researcher uses theory about typology of code-mixing as introduced by Muysken (2000) in analyzing code-mixing on Twitter tweets. Muysken (2000) introduces about code-mixing and its types: insertion, alternation, and congruent lexicalization.

Insertion is a type of code-mixing by interpolating elements of other languages into a sentence structure that uses a particular language. The insertion refers to the embedded linguistic elements of another language into a sentence of one language. Muysken (2000) also illustrates the structure of insertion code-mixing as $\mathrm{A}$ $-\mathrm{B}-\mathrm{A}$. $\mathrm{A}$ is the first language as primary language of a sentence and then follow by inserting another lexical of language that illustrate as B. Based on the grammatical rules, the elements before and after the insertion is related in the same context. Syafrizal \& Sari (2017) explain the function of insertion code-mixing is commonly purposed to insert foreign words as symbolic or to expand vocabulary.

Alternation occurs by transferring the clauses from first language into another language. Pratama \& Hastuti (2020) define alternation is a process of mixing two languages in the form of a clause alternately related. It includes mixing structures from two different languages in the form of clauses that remain related separately. Muysken (2000) gives illustration about alternation code-mixing. The structure illustrates as A-B. A refers to the first language and another language refers to B. Alternation begins with clause of language $\mathrm{A}$ and continues with the same forms from language B. Siddiq et al. (2020) explain that clause of language A and $B$ are switched structurally unrelated. The sentence starts with the first language and ends with the clause of another language. The relation between language $A$ and $B$ is undefined because there is no structural relationship in language. The alternation causes the change of language A into language $B$. Thus, it does not follow the grammatical rules.

Congruent lexicalization contains code-mixing between different languages by sharing the grammatical structures of both languages in one sentence. Muysken (2000) illustrates the congruent lexicalizations as $\mathrm{A}-\mathrm{B}-\mathrm{A}-\mathrm{B}$. As explained previously in the other types, $\mathrm{A}$ refers to one language, and $B$ is another language used by the speaker. Sutrisno \& Ariesta (2019) explain that congruent lexicalization inserts linguistic elements of language randomly between sentences of the primary language. The speaker generally inserts the linguistic aspects of another language randomly in the previous and following linguistic elements of the first language used. Congruent lexicalization covers two languages with a grammatical structure that shifts from one language to another. In a sentence, there 
are phrases or words from both languages. Therefore, the grammatical structure is divided between two languages inserted randomly in the same sentence or clause.

Some researchers have studied the same topic about code-mixing on social media. Al-Emran \& Al-Qaysi (2017) investigated attitudes among the students toward the use of code-mixing on social media in a higher educational setting. It focused on investigating the students' attitudes in using code-mixing as a language style for communication. The researcher used interviews and questionnaire to collect data from the participants. It found that the students highly used code-mixing on social media, especially in using Facebook and Whatsapp applications. Kurniawan (2016); Nova (2018) also studied code-mixing on Facebook among different languages. It focused on analyzing the update status and other interactions on Facebook that containing code-mixing. The finding showed that the common types of codemixing that arise were word, phrase, hybrid, and clause. These cases were affected by the lack of translation of language, learning habits, spontaneous action, and intention to mix language based on particular reasons.

The same study also has been done by Samhan (2017); Syafrizal \& Sari (2017), which studied the use of code-mixing through social media Twitter. The finding showed that the speakers of language used code-mixing for communication were influenced by several reasons, such as age, which could affect using code-mixing, gender, and education. Besides that, the advantages of mixing their language between the first languages with the English language could help them to improve their vocabulary and fluency to communicate using the English language in daily communication. Based on the background and studies above, this paper aims to identify the types of code-mixing used among twitter users in their tweets on the twitter platform to communicate in written form and investigate the factors that influence code-mixing among twitter users as language style.

\section{Research Method}

The study uses a descriptive qualitative research design and two kinds of data collection methods: documentation and interview. It tries to identify the types of code-mixing used in tweets posted by several Twitter users and investigate the factors influencing them to mix codes from different languages as language style in written communication through social media Twitter. The subject of this study is the Twitter users who posted tweets that contain code-mixing, and the object is the code-mixing in the tweets posted previously on the Twitter platform. The data collection instruments are documentation tools (hand-phone and computer) and an interview guide. Nuraeni et al. (2018) state, the researcher is the active respondent. Documentation uses to collect data of the tweets posted by Twitter users on Twitter platform by capturing and representing the tweets in the finding section. Meanwhile, the interview guide uses to ask questions to the respondents about the factor influencing them in mixing code from two different languages. The data collected are analyzed through three stages of qualitative data as introduced by Miles \& Huberman (as cited in Ongoz, 2018, p. 81). 
It includes data reduction, data display, and conclusion: drawing/verifying.

\section{Finding and Discussion}

\subsection{Types of Code Mixing among Twitter}

User
The researcher found various tweets related to code-mixing between Indonesian and English language among the Twitter users.

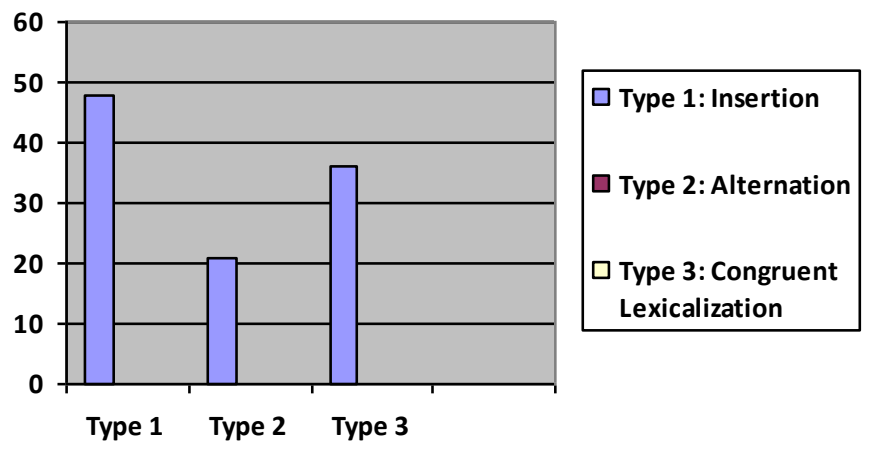

Figure 3.1 Number of Code Mixing in Tweet

From 105 tweets that have been documented by the researcher from the Twitter platform, around 48 tweets were categorized into insertion code-mixing. 21 tweets were considered into alternation code-mixing, and the rest that around 36 tweets were turned into congruent lexicalization code-mixing. The result showed that insertion became the common type used among bilingual people to communicate on Twitter. It got a similar finding with Safitri et al. (2017), who studied code-mixing in Facebook. The result showed that insertion and congruent lexicalization became the dominant types used among the respondents. Syafaat \& Setiawan (2019) the study of code-mixing in students' interaction on social media also stated that insertion and congruent lexicalization were the common types used in communication using code-mixing. The tweets from Twitter platform that contained code-mixing can be seen in the following table: 
Table 3.1 Types of Code Mixing in Tweets posted by Twitter Users

\begin{tabular}{|c|c|c|c|c|}
\hline \multirow[b]{2}{*}{ No } & \multirow[b]{2}{*}{ Tweets Posted by Users } & \multicolumn{3}{|c|}{ Types of Code Mixing } \\
\hline & & Insertion & Alternation & $\begin{array}{c}\text { Congruent } \\
\text { Lexicalization }\end{array}$ \\
\hline 1 & Aku rencana preloved baju yang jarang aku pakai & $\sqrt{ }$ & & \\
\hline 2 & Tetangga gw nyetel sweet home kenceng banget!! & $\sqrt{ }$ & & \\
\hline 3 & Lagi streaming nonton konser & $\sqrt{ }$ & & \\
\hline 4 & Cepet sembuh ya biar bisa skincare routine seperti biasa. & $\sqrt{ }$ & & \\
\hline 5 & Bakal jarang ada flash sale nih! & $\sqrt{ }$ & & \\
\hline 6 & Guys need your helps! Siapa tau ada yang butuh kerjaan. & & $\sqrt{ }$ & \\
\hline 7 & Tonight on Indonesian Idol, ga sabar banget gak sih? & & $\sqrt{ }$ & \\
\hline 8 & Don't expect too much, dia bisa berubah pikiran & & $\sqrt{ }$ & \\
\hline 9 & Don't worry about us, semangat nulis bukunya El! & & $\sqrt{ }$ & \\
\hline & Bahagiain diri sendiri dulu yuk, we can go through this! & & $\sqrt{ }$ & \\
\hline 19 & $\begin{array}{l}\text { Buat yang nyari crop top, cardigan yang murah yuk } \\
\text { mampir ke pinned tweet aku }\end{array}$ & & & $\sqrt{ }$ \\
\hline 20 & Sesama level manager antara HR dan Marketing bisa beda & & & $\sqrt{ }$ \\
\hline 22 & $\begin{array}{l}\text { Sebelum melakukan job grading, ada proses penentuan } \\
\text { apakah menggunakan narrow grade atau broad band grade }\end{array}$ & & & $\sqrt{ }$ \\
\hline 24 & Ada yang tau cara report atau take down berita gini gak sih? & & & $\sqrt{ }$ \\
\hline 28 & $\begin{array}{l}\text { Kalau kondisi lagi urgent, karyawannya mostly akan } \\
\text { maksain masuk kok }\end{array}$ & & & $\sqrt{ }$ \\
\hline
\end{tabular}

The tweets that were selected randomly contained the use of codemixing in different forms. The types of code-mixing used were differentiated into three major types: insertion, alternation, and congruent lexicalization code-mixing, and these were introduced by Muysken (2000). The primary language used was Indonesian and then inserted with words, phrases, and clauses from the English language. Twitter users posted tweets that used code-mixing at different times and dates. The analysis of code-mixing in some tweets can be seen as below:

Semoga ada countdown poster B.I dengan tema yang sama

Beberapa hari ini gue healing dan belajar dari pagi sampe sore

The tweets above were considered to use insertion code-mixing. The main language was Indonesian and then inserted with words (i.e., healing, B.I) and a phrase of countdown between the sentence structure. The words and phrase that inserted were accordances with the structure of insertion that introduced by Muysken (2000). The structure was A - B $A$, in which the inserted elements were put in between of sentence structure of the main language.

Udah gabisa sabar lagi, you all talking about my worst

Sabar kak rejeki gak akan kemana, don't give up!

The alternation code-mixing was used in the tweets stated above. An alternation code-mixing occurs when clauses from two languages with different grammatical structures appear alternately in the same sentence but relatively separate clauses (Pratama \& Hastuti, 2020). It often occurs in bilingual speakers who were stable against mixing languages in communication. The tweets above showed 
that clauses of English appeared after the clause of the Indonesian language, and both clauses were not related to grammatical rules. However, the meaning showed relation in the related context.

Ada knit jacket yang patternnya lidi dan timbul

Saya ada baju preloved, knitwear, boyfriend jeans semua ada!

The stated tweets above are categorized into congruent lexicalization code-mixing. It was indicated by the use of words and phrases that were put randomly in a single sentence. The words and phrase in tweets above related with the structure that introduced by Muysken (2000), the structure was A - B - A - B. Codes from English language were put in following and previous elements of the first language. Furthermore, tweets above also insert a hybrid form (pattern + nya), in which hybrid refers to a combination between the suffix of Indonesian language and word of English language.

Suwito (as cited in Sutrisno \& Ariesta, 2019) mentions some forms of linguistics elements commonly used in code-mixing. It includes words, phrases, clauses, idiom/expressions, hybrid, and reduplication. The hybrid means insertion in the form of a word by combining two elements of different languages, such as the prefix of Indonesian with English word into one word. Based on the data documented from the tweets by the researchers, the forms of linguistics elements used by the Twitter user were differentiated into several forms. It can be seen in the following figure:

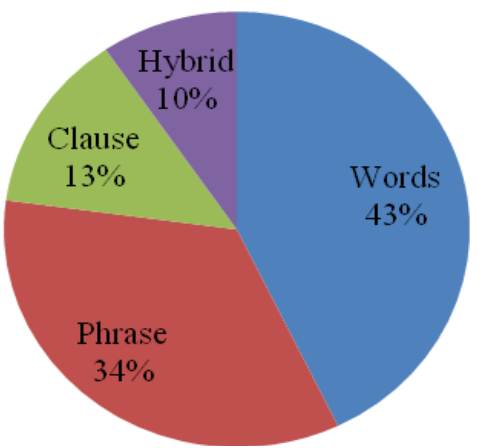

Diagram 3.2 Forms of Linguistic Elements in Code Mixing

From the diagram above, it can be seen that from 105 tweets, there were 43\% used words insertion of code-mixing, 34\% used phrase insertion, $13 \%$ of tweets used clause insertion in mixing codes of two languages in posting a tweet on Twitter platform, and $10 \%$ used hybrid insertion in their tweets. It was indicated that words become the simplest and general form used to mix the code from two different languages, especially Indonesian and English. Moreover, code-mixing frequently appeared in informal communication, such as communication in social media rather than formal. Sutrisno \& Ariesta (2019) state that informal language is generally used in daily contexts that is more casual and not bound by grammatical language rules. Therefore, code-mixing commonly occurrs in social media communication, such as on Twitter platform.

\subsection{Factors Influencing the Use of Code Mixing}

The interview results with six respondents as Twitter users got data about factors influencing the use of codemixing for written Communication through Twitter. The factors are: 


\section{Bilingualism}

The ability of people to communicate in more than one language can influence the use of code-mixing (Sutrisno \& Ariesta, 2019). Their ability to communicate in different languages gives a chance for code-mixing to occur in Communication through social media Twitter. Furthermore, Sutrisno \& Ariesta (2019), who investigated the same case, indicated that people use code-mixing because they cannot find the appropriate word in the same language. They need to adopt codes from the other language. The lack of vocabulary of the primary language combined with knowledge of another language influences the speaker to transfer codes/vocabulary from another language (Sutrisno \& Ariesta, 2019b). Safitri et al. (2017) also found that the use of codemixing purposed to improve their English skills in Communication. It was related to the interview result with respondents who stated that English was an essential subject in an educational context that should be mastered.

\section{Social environment}

The use of code-mixing also frequently occurs due to the influence of social environment. When people live around bilingual people, they intentionally communicate in different languages as the other. Nuraeni et al. (2018) stated that the use of code-mixing is affected by social environment where the language speakers live. When they do Communication with others, they will use what language they have mastered previously. The social environment can influence how language speakers mix their language in Communication. It is also supported by technology development, giving language speakers a chance to improve language skills quickly.

\section{Speaking Partner}

Language speakers generally have particular partners speaking to communicate, and different partners can influence how a language speaker speaks with language style. Sutrisno \& Ariesta (2019) mention that code-mixing frequently depends on who the partner is speaking to communicate for sharing an idea or talking about a certain topic. Moreover, how a language speaker uses code-mixing also influences the topic the language speaker and partner speaking is talking about. Silaban \& Marpaung (2020) explain that code-mixing arises when the language speaker wants to express emotion and emphatic intentionally by transferring code from another language.

Context of Communication

The situation is one factor influencing the use of code-mixing to communicate in social media. Moreover, communication in social media considers informal communication. It affects the language speaker to mix differently in communication because they do not require following the grammatical rules of both languages. Besides that, people also want to keep their conversations private while communicating on social media by mixing the code of both languages (Nuraeni et al., 2018). Based on the situation, code-mixing also uses to strengthen the expression of the speaker (Safitri et al., 2017). For instance: showing a joke, emotion, and other.

\section{Prestige}

In particular context, language style becomes an identity of language speakers 
and shows the personality. Most of the language speakers who are bilingual and multilingual prefer to communicate using code-mixing to show the ability to communicate in more than one language. This phenomenon shows there is prestige among the language speaker in communication. Using code-mixing as a language style can show the modernity of language speakers to follow the globalization era (Sutrisno \& Ariesta, 2019).

The interview result showed that code-mixing is seen as a spontaneous thing rather than by specific mechanism rules (Anastassiou \& Andreou, 2017). Language style tends to share thoughts in communication with others since linguistics globalization (Jimmi \& Davistasya, 2019). It becomes a natural thing to do in communication to meet interdependence for people who communicate in more than one language and become a language style in the social community among the bilingual and multilingual speakers (Silaban \& Marpaung, 2020). Furthermore, Purnama (2020) mentions that the speaker becomes more comfortable mixing more than one language. It is mixing two different language purposes to improve the ability and gain enjoyment in communication.

\section{Conclusion}

Based on the topic discussed above, cultural and linguistic globalization influences language use in society. It increases the phenomenon of code-mixing in daily communication orally or in written form. Code-mixing generally categorized into several types, which differentiate from one another in analyzing the phenomenon of code-mixing in communication. This topic has been studied by other researchers but in a different area and particular aspect. The use of code-mixing does not determine by gender, age, or level strata. It naturally and intentionally occurs among the language speaker who can communicate in different languages. Based on the analysis above, the types of code-mixing among Twitter users were dominantly categorized into insertion code-mixing. The common form of linguistic elements inserted into the first language is words, phrases, and clauses. It influences by various factors around the language speakers that give a chance to communicate by using code-mixing.

\section{References:}

Al-Emran, M., \& Al-Qaysi, N. (2017). Code-switching usage in social media: a case study from Oman knowledge management view project Arabic natural language processing tools view project code-switching usage in social media: a case study from Oman. International Journal of Information Technology and Language Studies (IJITLS), 1(1), 2538. http://journals.sfu.ca/ijitls

Anastassiou, F., \& Andreou, G. (2017). Factors associated with the code mixing and code switching of multilingual children: an switching of multilingual children: an overview. International Journal of Linguistics, Literature and Culture (LLC), 4(3), 2518-3966.

Jimmi, \& Davistasya, R. E. (2019). Codemixing in language style of south jakarta community indonesia. Premise: Journal of English Education, $\quad 8(2), \quad 193-213$. https://doi.org/10.24127/pj.v8i2.2219

Kurniawan, B. (2016). Code-mixing on facebook postings by efl students: a small scale study at an smp in tangerang. Indonesian JELT, 11(2), 169-180. 
https://doi.org/10.25170/ijelt.v11i2.8 28

Leung, C. H., \& Chan, W. T. Y. (2016). Sociolinguistic Phenomenon of Code Mixing in Hong Kong: From a Perspective of Marketing Communications. Humanities \& Social Sciences Reviews, 4(1), 20 26. https://doi.org/10.18510/hssr.2016.41 3

Muysken, P. (2000). Bilingual speech: a typology of code mixing. Cambridge: Cambridge University Press.

Nova, M. (2018). Code Mixing in Social Media: Balinese Language, Indonesian Language, and English. IMPACT: International Journal of Research in Humanities, Arts and Literature (IMPACT: IJRHAL), 6(5), 47-58.

http://www.impactjournals.us/archiv es.php?year=2018_11_2\&id=11\&jty $\mathrm{pe}=2 \&$ page $=14$

Nuraeni, B. L., Farid, M. Z., \& Cahyati, S. S. (2018). The use of indonesian english code mixing on instagram captions. PROJECT (Professional Journal of English Education), 1(4), 448-453.

https://doi.org/10.22460/project.v1i4. p448-453

Ongoz, S. (2018). The use of ict tools in e-mentoring: a case study. Turkish Online Journal of Distance Education, 19(4), 76-89. https://doi.org/10.17718/tojde.47165 5

Pratama, R. M. D., \& Hastuti, D. P. (2020). Code mixing and code switching in twivortiare 2 novel by ika natassa. Wanastra: Jurnal Bahasa Dan Sastra, 12(2), 288-295. https://doi.org/10.31294/w.v12i2.899 6

Purnama, A. V. (2020). The perception of efl students to the use of codeswitching in classroom. Jurnal Sphota, 12(2), 52-61. https://doi.org/10.36733/sphota.v12i 2.944

Safitri, L., Harida, E. S., \& Hamka. (2017). The analysis of code mixing on students' facebook: a study on facebook status and comments of the sixth semester students tbi iain padangsidimpuan. English Language Teaching and Research, I(1), 164175.

Samhan, A. H. (2017). Social aspects in social media: code switching and code mixing in twitter. Research on Humanities and Social Sciences, 7(18), 110-115.

Sebba, M., Mahootian, S., \& Jonsson, C. (2012). Language mixing and codeswitching in writing: approches to mixed language written discourse (1st ed.). New York: Routledge.

Siddiq, R. A., Kustati, M., \& Yustina, L. S. (2020). Teachers' code mixing and code switching: insights on language barriers in efl classroom. Al-Ta Lim Journal, 27(1), 80-91. https://doi.org/10.15548/jt.v27i1.606

Silaban, S., \& Marpaung, T. I. (2020). An analysis of code mixing applied by indonesia lawyers club program on tv one. Journal of English Teaching as Foreign Language, 6(3), 1-17. http://repositori.usu.ac.id/handle/123 456789/18501

Sutrisno, B., \& Ariesta, Y. (2019). Advances in Language and Literary Studies Beyond the use of Code Mixing by Social Media Influencers in Instagram. Advances in Language and Literary Studies, 10(6), 143151.

Sutrisno, B., \& Ariesta, Y. (2019). Beyond the use of code mixing by social media influencers in instagram. Advances in Language and Literary Studies, 10(6), 143151.

https://doi.org/10.7575/aiac.alls.v.10 n.6p. 143

Syafaat, P. M. F., \& Setiawan, T. (2019). An analysis of code mixing in 
twitter. Advances in Social Science, Education and Humanities Research, 297, 276-281. https://doi.org/10.2991/icille18.2019 .57

Syafrizal, \& Sari, A. R. (2017). Code mixing in students' twitter status at sultan ageng tirtayasa university in banten, indonesia. European Journal of Foreign Language Teaching, 2(1), $117-135$

https://doi.org/10.5281/zenodo.3456

22 